\title{
Student Nurse Perceptions of Video Simulation and Critical Reflection for Developing Clinical- Reasoning Skills: A Cross Cohort Study
}

\author{
Michael J. Macartney, Pathmavathy Namasivayam and John F. Cooper \\ University of Tasmania, Australia
}

\begin{abstract}
Clinical-reasoning (CR) provides a framework for higher-order critical thinking that fosters a nurse's ability to assess, process and remedy clinical encounters and is considered essential for the provision of quality healthcare. This study aimed to determine whether student nurses regard the inclusion of video-simulation with critical-reflection as a valuable opportunity to develop their CR skills. An existing case-based assessment was redesigned to include short video-simulations where deliberate but subtle CR flaws were included, requiring students to identify strengths and weaknesses of their own CR process. Following completion of the assessment a modified student satisfaction and selfconfidence Likert scale survey with open-ended questions was conducted to identify perceptions towards the assessment task. Incorporating video-simulation and critical-reflection was perceived as a useful opportunity to develop CR skills by student nurses. Albeit, students studying in a traditional three year Bachelor of Nursing cohort were more positive of the opportunity than their peers in a two year fast-track cohort.
\end{abstract}

Keywords: Nurses; education; technology enhanced learning; student perspective.

\section{Introduction}

The clinical-reasoning (CR) cycle provides an important framework to build higher order thinking skills which foster a nurse's ability to assess, process and remedy a clinical situation (Levett-Jones et al., 2010). Effective CR is associated with the provision of quality health care and patient outcomes, whereas nurses with poorly developed CR skills often compromise patient safety and worsen patient outcomes (Aiken et al., 2003; Kavanagh \& Szweda, 2017). Consequently, developing effective CR skills in undergraduate student nurses is of great importance. Within contemporary nursing education, a range of teaching approaches are used including case-based learning (Yoo \& Park, 2015), and simulation technologies (Cant \& Cooper, 2017) to facilitate a requisite level of CR skills before students undertake clinical placements. However, identifying novel or adapting existing teaching and learning strategies to effectively develop CR skills in student nurses is an on-going focus of research completed within nursing education.

Typically, case-based learning is paper-based and students either independently, or as a group, speculate on a course of action based on provided clinical information. While this offers an effective method to improve student cognitive knowledge within a classroom setting, there is evidence this type of learning does not translate into clinical practice (Scully, 2011). Within nursing 
curricula, it is paramount teaching and learning strategies prepare and empower students to undertake their clinical placements. Clinical placements form a core, integral component of Bachelor of Nursing degree structure (Doyle et al., 2017) with its key purpose to translate theoretical knowledge from the tertiary environment to the clinical environment and allow students to develop their professional identity and competence (Arieli, 2013; Henderson et al., 2012). As such, enhancing student perception of learning experiences using technologies, such as video-simulation, offers a method to support learning beyond the classroom, and therefore may provide a method to link the acquisition of cognitive knowledge related to CR directly to skills in practice. In line with this, it has recently been concluded that while further research is needed, the use of videos in nursing education is a promising strategy which could enhance learning of CR skills (Forbes et al., 2016).

Many studies have investigated different methods to assess and promote student learning within health-related courses (Epstein, 2007; Norcini \& McKinley, 2007). The use of videos (known specifically in this context as 'vignettes'), has previously been advocated as a successful way of both engaging students to learn (Ventura \& Onsman, 2009) and assisting to assess the perception of a student's knowledge on what they are visualising (Carvalho et al., 2017). Further, it has also been suggested that the use of videos can make existing paper-based case-studies more immersive and empower students to apply knowledge gained through other modes of teaching (Beckem \& Watkins, 2012). However, in the context of learning CR skills that are transferable to practice, it remains unclear whether the inclusion of critical reflection upon video-simulation as part of a casestudy assessment task is perceived as a valuable learning opportunity by student nurses.

At the university where this study took place, the Bachelor of Nursing degree is delivered over six semesters of study total. However, students have the option of completing their degree over a 'traditional' three years (two semesters per calendar year) or two years as a 'fast-track' option (three semesters per calendar year). In order to accommodate the additional semester in the calendar year, the latter option provides shorter breaks between each semester of study and the third semester is 10 weeks in length rather than 13. To the authors' knowledge, no studies have investigated whether the structure of a student's degree influences their perception of activities designed to enhance learning of CR skills. This is a critical knowledge gap, because it is well documented there is no 'one size fits all' strategy for teaching and learning (Schmeck, 2013) and approaches to learning are influenced by situational factors such as 'time-pressure' (Chin \& Brown, 2000) imposed by scheduling within the degree course and unit structure.

\section{Assessment Task}

A pre-existing assessment task was redesigned to include video-simulation as an opportunity for critical-reflection in line with the intended learning outcomes of the unit. The assessment task required students to use the CR framework (Levett-Jones et al., 2010) to analyse a paper-based patient case-study. As part of the case-study students were asked to make an informed clinical judgement to identify the priority nursing issues for the patient and then which of the short video-simulations (each depicting an individual skill linked to those priority nursing issues) is the most appropriate to undertake. The video-simulations depicted a Registered Nurse (RN) undertaking specific bedside skills relevant to the case-study which deliberately provide both evidence-based and unsafe approaches to care whilst performing the skill. Students were required to write a short (250-word) critical-reflection upon the video to examine which components of the nurses' practice are evidence-based and which could be considered unsafe and how this might impact patient outcomes, as well as their own future practice.

\section{$\operatorname{Aims}$}

In this study, upon completion of the assessment task, students enrolled in both the traditional and fast-track Bachelor of Nursing degree were surveyed to investigate their perception towards the effectiveness of the assessment task in combination with the video-simulation for developing their own CR skills. Consequently, we tested the following hypotheses:

H-1. Overall, all students would support the inclusion of critical-reflection upon video-simulations, as part of the assessment task, to develop their own CR skills;

H-2. Students in the fast-track degree, with many competing time-demands, may not value the assessment task the same way as their peers in a traditional degree. 


\section{Methods}

\section{Study Overview}

This study evaluated student perceptions towards the inclusion of critical-reflection upon a video-simulation, in a multi-modal assessment task, as a learning tool to facilitate recognition and application of CR during their clinical placement within a regional Australian context. To evaluate perceptions, anonymous surveys were distributed to students in the first week returned from holidays. This occurred following the completion of their clinical placement, final semester exams, release of results and conclusion of the unit in which the assessment task was completed.

\section{Ethical Considerations}

The University of Tasmania Social Sciences Research Ethics Committee granted approval for the study (ethics \#: H0017888). A comprehensive participant information sheet was provided to all students as part of the survey distribution. To alleviate any perceived power relationships between faculty and students, the surveys were distributed by a non-academic member of staff who was not involved with the study. Students were informed completion was voluntary and non-completion would not prejudice their progress in the nursing programme. Students who returned completed surveys were deemed to have consented.

\section{Sample Size}

Nursing students which had completed the assessment task as part of a $2^{\text {nd }}$ year unit were invited to participate in the research study. This included a traditional cohort of Bachelor of Nursing $(\mathrm{BN})$ degree $(n=175)$ and the fast-track BN degree $(n=110)$ for a total of eligible participants $(n=285)$.

\section{Survey Design}

Likert-scale responses were used to investigate student agreement (one: strongly disagreed; two: disagree; three: undecided; four: agree; five: strongly agreed; NA: not applicable) with sixteen statements regarding the assessment task and videosimulation. The statements were adapted from the National League of Nursing Student Satisfaction and Self-confidence in Learning survey ${ }^{1}$ and designed to investigate perceptions of different overarching themes. Consultation with other senior and experienced staff within the School of Nursing (that were not investigators on the project) was completed during development of the survey to identify and address any issues of validity and reliability before the survey was distributed to students. Statements one to five were related to the assessment task design; statements six and seven were related to collaboration; statements eight and nine were related to integration of Bioscience/Nursing content; statements 10-12 were related to the inclusion of videos in the assessment task; statements thirteen to sixteen were related to facilitation of CR during clinical placement (Table 1). Additionally, Likert-scale responses were used to investigate student perceptions of importance (one: not important; two: somewhat important; three: neutral; four: important; five: very important) for the same sixteen statements. This component of the survey asked students to rate each statement based upon how important the statement was to them. This was included to identify what student nurses perceive as the most important aspects of the assessment task and for the development of CR skills. For example, a student may strongly disagree that the video-simulation in the current iteration of the assessment task provided an opportunity to recognise strengths and weakness in their own nursing skills but, using the importance scale, can indicate that they believe this is a highly important component to developing their CR skills. Accordingly, researchers can use this type of feedback to identify and focus attention on specific aspects needing modification to optimise the assessment task for future students. Finally, directly following each statement space was provided for students to provide open-ended responses.

\section{Data Analysis}

Descriptive statistics were calculated from data collected from consenting participants (fast-track: $n=68$; traditional: $n=116$; total $n=184$ ) to identify overall student perception of the multi-modal assessment task. Comparisons were conducted between the fast-track and traditional learning cohorts using Mann Whitney-U $t$-tests for independent groups as the samples were not

${ }^{1}$ http://www.nln.org/professional-development-programs/research/tools-and-instruments/descriptions-of-available-instruments 
normally distributed. Alpha for significance was set at $p<0.05$, with data being reported as means $( \pm \mathrm{SD})$. All analyses were performed using GraphPad Prism version 8 (GraphPad Software, La Jolla, California, USA).

\section{Results}

The frequencies and response rate (\%) of student feedback to the Likert-scale agreement statements are outlined in Table 1. The strongest levels of agreement were observed for statement three, eight and eleven. The strongest levels of disagreement were observed for statements fourteen and sixteen. The mean agreement and importance for each sub-set of statements making up a theme are shown in Table 2. Mean agreement was highest for statements six and seven relating to collaboration and lowest for statements eight and nine relating to the integration of Bioscience and Nursing content. Mean importance was highest for statements 10-12 relating to the effectiveness of videos and lowest for statements one - five relating to assessment design.

\section{Table 1}

Frequencies and Response Rate to Survey Statements

\begin{tabular}{|c|c|c|c|c|c|c|c|}
\hline Statement & $N$ & $\begin{array}{l}\text { Strongly } \\
\text { disagree }\end{array}$ & Disagree & Undecided & Agree & $\begin{array}{l}\text { Strongly } \\
\text { agree }\end{array}$ & N/A \\
\hline $\begin{array}{l}\text { 1. I clearly understood the purpose and objectives of the } \\
\text { assessment task }\end{array}$ & 183 & $5(3 \%)$ & $19(10 \%)$ & $38(21 \%)$ & $85(46 \%)$ & $36(20 \%)$ & 1 \\
\hline $\begin{array}{l}\text { 2. The assessment task provided enough information in a clear } \\
\text { manner to facilitate a clinical reasoning approach to the case-study }\end{array}$ & 183 & $8(4 \%)$ & $30(16 \%)$ & $48(26 \%)$ & $63(34 \%)$ & $32(17 \%)$ & 1 \\
\hline $\begin{array}{l}\text { 3. The case-studies were appropriate and relevant to develop my } \\
\text { clinical reasoning skills }\end{array}$ & 181 & $3(2 \%)$ & $15(8 \%)$ & $15(8 \%)$ & $80(44 \%)$ & $68(38 \%)$ & 3 \\
\hline $\begin{array}{l}\text { 4. Independent clinical reasoning was facilitated through the } \\
\text { resources made available for the assessment task }\end{array}$ & 179 & $4(2 \%)$ & $25(14 \%)$ & $62(35 \%)$ & $60(34 \%)$ & $28(16 \%)$ & 5 \\
\hline $\begin{array}{l}\text { 5. The multi-modal approach to this assessment task was } \\
\text { beneficial to my learning experience }\end{array}$ & 175 & $10(6 \%)$ & $26(15 \%)$ & $44(25 \%)$ & $49(28 \%)$ & $46(26 \%)$ & 9 \\
\hline $\begin{array}{l}\text { 6. I collaborated with my peers to inform my understanding of the } \\
\text { case-study }\end{array}$ & 179 & $16(9 \%)$ & $22(12 \%)$ & $26(15 \%)$ & $47(26 \%)$ & $68(38 \%)$ & 5 \\
\hline $\begin{array}{l}\text { 7. Collaboration with my peers helped to guide my learning of } \\
\text { clinical reasoning }\end{array}$ & 175 & $9(5 \%)$ & $23(13 \%)$ & $24(14 \%)$ & $52(30 \%)$ & $67(38 \%)$ & 9 \\
\hline $\begin{array}{l}\text { 8. The assessment task integrated Bioscience and Nursing content } \\
\text { to develop independent clinical reasoning skills }\end{array}$ & 180 & $8(4 \%)$ & $13(7 \%)$ & $33(18 \%)$ & $63(35 \%)$ & $63(35 \%)$ & 4 \\
\hline $\begin{array}{l}\text { 9. The assessment task enabled me to extend my understanding } \\
\text { and application of the clinical reasoning cycle from learning } \\
\text { undertaken in previous semesters. }\end{array}$ & 181 & $9(5 \%)$ & $21(12 \%)$ & $41(23 \%)$ & $64(35 \%)$ & $46(25 \%)$ & 3 \\
\hline $\begin{array}{l}\text { 10. The videos were a useful resource as part of the assessment } \\
\text { task }\end{array}$ & 181 & $17(9 \%)$ & $20(11 \%)$ & $45(25 \%)$ & $46(25 \%)$ & $51(28 \%)$ & 3 \\
\hline $\begin{array}{l}\text { 11. The videos enabled me to recognise strengths and weakness in } \\
\text { the nursing skill demonstrated }\end{array}$ & 181 & $11(6 \%)$ & $10(6 \%)$ & $33(18 \%)$ & $60(33 \%)$ & $67(37 \%)$ & 3 \\
\hline $\begin{array}{l}\text { 12. The videos developed my ability to apply clinical reasoning } \\
\text { skills }\end{array}$ & 180 & $14(8 \%)$ & $18(10 \%)$ & $45(25 \%)$ & $73(41 \%)$ & $30(17 \%)$ & 4 \\
\hline $\begin{array}{l}\text { 13. The assessment task raised my awareness to better recognise } \\
\text { clinical reasoning encounters during my placement }\end{array}$ & 177 & $14(8 \%)$ & $18(10 \%)$ & $40(23 \%)$ & $59(33 \%)$ & $46(26 \%)$ & 7 \\
\hline $\begin{array}{l}\text { 14. The assessment task helped me recognise strengths and } \\
\text { weaknesses of my own nursing practice during my placement }\end{array}$ & 175 & $15(9 \%)$ & $21(12 \%)$ & $31(18 \%)$ & $66(38 \%)$ & $42(24 \%)$ & 9 \\
\hline $\begin{array}{l}\text { 15. The assessment task helped me recognise strengths and } \\
\text { weaknesses of the nursing practice of others within my placement } \\
\text { environment }\end{array}$ & 177 & $13(7 \%)$ & $17(10 \%)$ & $44(25 \%)$ & $55(31 \%)$ & $48(27 \%)$ & 7 \\
\hline $\begin{array}{l}\text { 16. This assessment task developed my confidence to engage in } \\
\text { clinical reasoning encounters in placement }\end{array}$ & 177 & $20(11 \%)$ & $23(13 \%)$ & $47(27 \%)$ & $57(32 \%)$ & $30(17 \%)$ & 7 \\
\hline
\end{tabular}

Notes: Frequencies and response rate (\%) to survey statements are categorised according to assessment task design (statement 1-5), collaboration (statement 6\&7), integration of bioscience (statement 8\&9), effectiveness of videos (statement 10-12) and facilitation of clinical reasoning during clinical placement (statement 13-16). 
Table 2

Agreement and Importance Scores According to Statement Themes

\begin{tabular}{|l|c|c|}
\hline Statement theme & $\begin{array}{c}\text { Mean } \\
\text { agreement }\end{array}$ & $\begin{array}{c}\text { Mean } \\
\text { Importance }\end{array}$ \\
\hline Assessment design (statements 1-5) & $3.75(0.20)$ & $3.96(0.13)$ \\
\hline Collaboration (statements 6\&7) & $3.78(0.05)$ & $4.03(0.08)$ \\
\hline Integration of Bioscience and Nursing content (statements 8\&9) & $3.50(0.16)$ & $4.24(0.37)$ \\
\hline Effectiveness of videos (statements 10-12) & $3.66(0.43)$ & $4.46(0.12)$ \\
\hline Facilitation of CR during placement (statements 13-16) & $3.73(0.23)$ & $4.27(0.09)$ \\
\hline
\end{tabular}

Notes: Data presented are mean $( \pm \mathrm{SD})$. See Table 1 for specific details about each statement. CR, clinical reasoning.

Examination of the agreement scores by learning cohort demonstrated some differences (Fig. 1). Relative to students in the traditional BN cohort $(n=116)$, the fast-track cohort $(n=68)$ demonstrated significantly $(P<0.05)$ lower agreement scores for statements eleven and thirteen - fifteen. There were no other differences in agreement scores between the two cohorts for any other statement. Finally, examination of the mean score for students perceived importance of each statement by learning cohort depicted in Figure 2. Relative to students in the traditional BN cohort, the fast-track cohort demonstrated significantly $(P<0.05)$ higher perceived importance for statements one - four and nine.

\section{Figure 1}

Agreement Scores in Response to each Survey Statement for both Student Cohorts

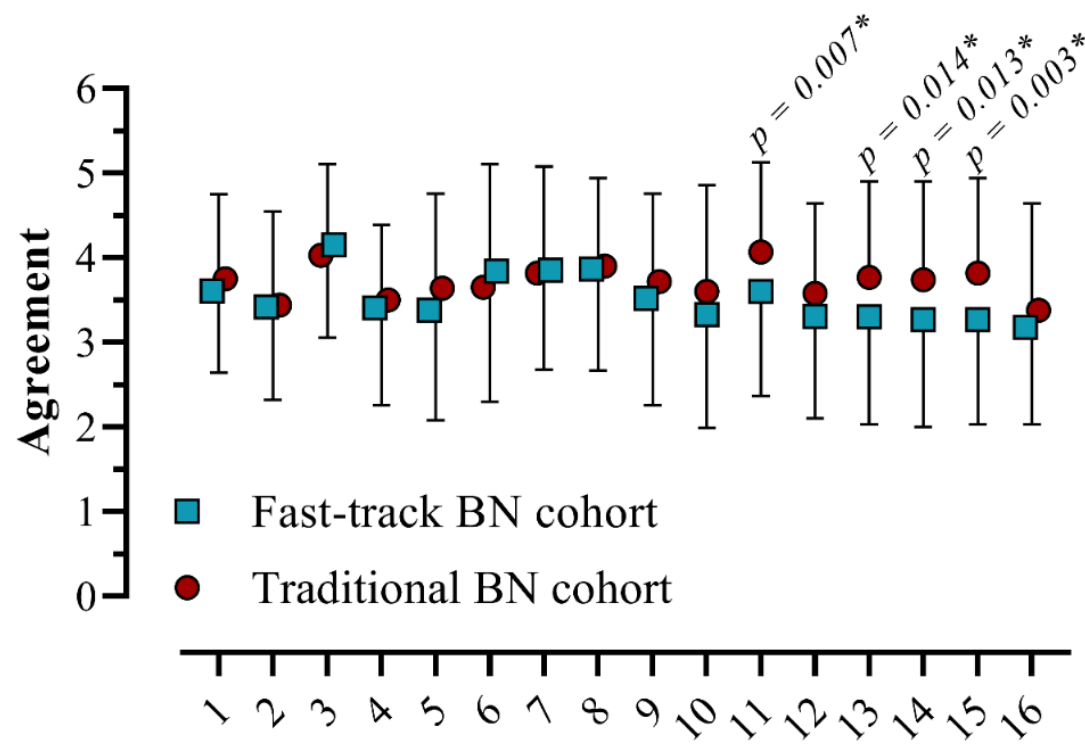

Statement

Notes: Data presented are mean $( \pm \mathrm{SD})$ for fast-track $(n=68)$ and traditional $(n=116)$ Bachelor of Nursing $(\mathrm{BN})$ cohorts. See Table 1 for specific details about each statement. *Indicates a significant difference $(P<0.05)$ between cohorts using a Mann Whitney-U test. 
Figure 2

Agreement Scores in Response to each Survey Statement for both Student Cohorts

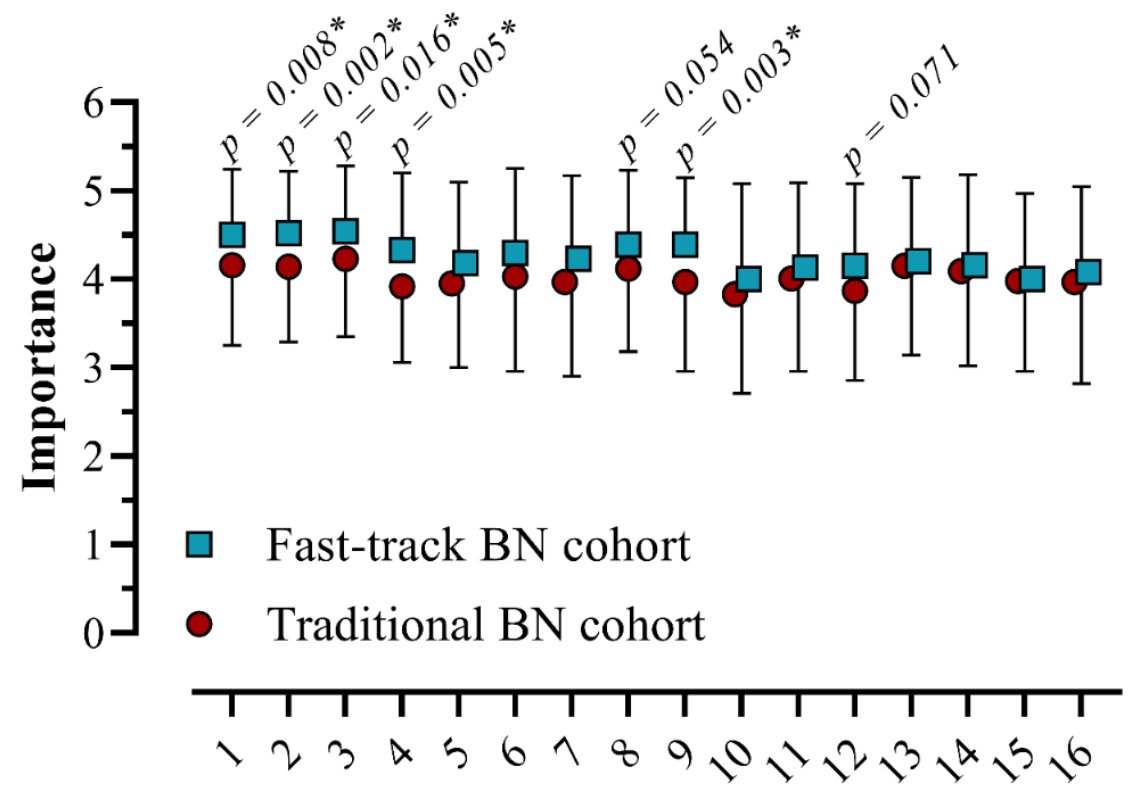

Statement

Notes: Data presented are mean $( \pm \mathrm{SD})$ for fast-track $(n=68)$ and traditional $(n=116)$ Bachelor of Nursing $(\mathrm{BN})$ cohorts. See Table 1 for specific details about each statement. *Indicates a significant difference $(P<0.05)$ between cohorts using a Mann Whitney-U test.

\section{Discussion}

In support of our first hypothesis $(H-1)$, results from this study demonstrate that irrespective of cohort, student nurses strongly perceived that critical-reflection based upon video-simulation and the multi-modal assessment activity was beneficial for and is appropriate to develop their CR skills. Further, an unanticipated strength identified by the survey was the assessment task appeared to stimulate student collaboration in learning CR skills. Notwithstanding the favourable aspects highlighted, there was some disagreement from students that the assessment task prepared them for identification and use of CR skills in practice that may be linked to a bioscience knowledge-nursing practice relationship disconnect. Finally, in line with our second hypothesis $(H-2)$, comparison of perceptions between cohorts indicated student nurses from the traditional and fast-track cohorts had differing opinions on certain areas of the assessment task, underscoring that tailoring of the activity is necessary.

A major theme identified in this study was that despite strong student agreement for the assessment task and use of videosimulation as an appropriate method to develop and recognise CR, this did not translate into their ability to confidently use CR skills in clinical placement. This was reflected by anecdotal comments in the open-ended responses where students stated "the knowledge [clinical reasoning] was very useful" but still felt as though they had "very little confidence" to engage in CR encounters in practice. This highlights an on-going problem contemporary nursing education struggles with commonly referred to as the "preparation-to-practice gap" (Kavanagh \& Szweda, 2017), whereby theory is not efficiently translated into clinical situations. This gap is of particular interest to teachers, health professionals and government, as CR skill acquisition is an essential part of competent nursing practice (Hur \& Roh, 2013). It has been established that a strong grounding in science is an essential component of a nursing degree and that the link between bioscience knowledge and nursing practice is critical for building confidence levels in student nurses on placement (Ralph et al., 2017). In the current study, the combined agreement score was lowest for statements eight and nine, related to the integration of Bioscience and Nursing content (Table 2). However, 
students rated the same statements as a highly important component for learning CR skills. As such, it appears that student nurses from this study identified value in the bioscience knowledge-nursing practice relationship while indicating that improvements can be made in this area within the assessment task and video-simulations. Using a 'team teaching' approach with a broad range of expertise across staff has been demonstrated as one of several effective methods to ensure the depth and delivery of bioscience content is appropriate (Craft et al., 2013). Accordingly, future studies could investigate if including bioscience teaching team members, alongside the $\mathrm{RN}$, in the video-simulation is an effective strategy to bridge the bioscience knowledge-nursing practice gap.

Interestingly, a novel outcome from our study which may, in part, explain a contributing factor to the "preparation-to-practice gap' was that the survey demonstrated student nurses from the traditional (three-year) cohort agreed more strongly the assessment task was useful in facilitating CR during clinical placement (Figure 1, statements 13-15), relative to their peers in the fast-track (two-year) cohort. This difference in opinion was despite overall agreement indicating students predominantly agreed the assessment task design was satisfactory, irrespective of cohort. It is well-established that student approaches to learning are influenced by the learning situation (Chin \& Brown, 2000), with one of many key situational factors being time pressures. Anecdotal evidence of perceived time pressure is found in an open-ended response from a student in the fast-track cohort wrote, "used a script like approach to get it [the assessment task] over and done with ". It has been demonstrated in trainee doctors that perceived lack of time can result in reliance on "surface learning' techniques and reduce awareness of the learning opportunities available (Salamonson et al., 2013).

A 'rushed' approach may partially explain why the fast-track cohort placed significantly more importance on the assessment task design (Figure 2, statements one-four) than their peers in the traditional cohort. Anecdotal evidence indicates fast-track students were frustrated because the task "wasn't clear enough" or "there weren't enough resources + information available", whereas students in the traditional cohort appeared to better engage and understand the content which was available as part of the task. As such, implementation of approaches which aim to alleviate real- or perceived-time pressures, such as including a brief assessment task planning schema to aid with time-management, could improve satisfaction levels for student nurses in the fast-track cohort and potentially start bridging the 'preparation-to-practice gap'.

\section{Limitations}

Differences in the pathway of fast-track and traditional cohorts (13 weeks versus. 10 weeks, respectively) necessitated the distribution of the survey to students during different conditions. Surveys were distributed to both cohorts in the first week of their return from holidays following the completion of clinical placement, final semester exams, release of results and conclusion of the unit. However, students in the fast-track cohort have only one week of holidays, whereas students in the traditional cohort have three weeks. Survey questions can evoke an emotional response in participants (Glasow, 2005), if this occurred in our study, it is likely this amplified negative responses from students in the fast-track course as this is a particularly busy and stressful time in their degree program. However, it is important to recognise there is no 'ideal' time to survey student nurses from the fast-track cohort as their study load is extended throughout the majority of the year. Furthermore, whilst our study highlights some interesting student nurse perceptions towards video-simulation it should be noted that this survey was about one specific assessment task and students' perceptions of it at one university. Accordingly, and in combination with the subjectivity of survey responses, the results identified in our study are not generalisable across other cohorts and universities.

\section{Conclusion}

Adaptation of the existing assessment task using contemporary and technologically enhanced video-simulations was completed with the aim to enhance CR skills in student nurses. The observations of this study suggest the use of video-simulation in the updated multi-modal assessment task seems to be a promising, relevant and an important learning design strategy to facilitate learning of CR skills and peer collaboration. Albeit, while the assessment task was the same for both cohorts, the experience was different, with students from the traditional cohort gaining more from it, whereas their peers in the fast-track cohort being more critical of it. In line with this observation, further research is warranted to identify whether design adjustments which incorporate 'team teaching' to bridge the bioscience knowledge-nursing practice relationship or methods to alleviate timepressure are perceived as positive adjustments to enhance learning of CR skills in student nurses. 


\section{Acknowledgements}

We thank all the participants who volunteered for the present study and Mr Bob Wylie for his assistance developing, editing and producing the videos.

\section{Author contributions}

All named authors contributed substantially to (a) the conception and design, acquisition of data, or analysis and interpretation of data; (b) drafting the article or revising it critically for important intellectual content; (c) final approval of the version to be published.

\section{References}

Aiken, L. H., Clarke, S. P., Cheung, R. B., Sloane, D. M., \& Silber, J. H. (2003). Educational levels of hospital nurses and surgical patient mortality. Journal of the American Medical Association, 290(12), 1617-1623. https://doi.org/10.1001/jama.290.12.1617

Arieli, D. (2013). Emotional work and diversity in clinical placements of nursing students. Journal of Nursing Scholarship, 45(2), 192-201. https://doi.org/10.1111/jnu.12020

Beckem, J. M., \& Watkins, M. (2012). Bringing life to learning: Immersive experiential learning simulations for online and blended Courses. Journal of Asynchronous Learning Networks, 16(5): 61-70. http://dx.doi.org/10.24059/olj.v16i5.287

Carvalho, E. C., Oliveira-Kumakura, A. R. S., \& Morais, S. C. R. V. (2017). Clinical reasoning in nursing: teaching strategies and assessment tools. Revista Brasileira de Enfermagem, 70(3), 662-668. https://doi.org/10.1590/0034-7167-2016-0509

Cant, R. P., \& Cooper, S. J. (2017). Use of simulation-based learning in undergraduate nurse education: An umbrella systematic review. Nurse Education Today, 49, 63-71. https://doi.org/10.1016/j.nedt.2016.11.015

Chin, C., \& Brown, D. E. (2000). Learning in science: A comparison of deep and surface approaches. Journal of Research in Science Teaching, 37(2), 109-138. https://doi.org/10.1002/(sici)1098-2736(200002)37:2<109::Aid-tea3>3.0.Co;2-7

Craft, J., Hudson, P., Plenderleith, M., Wirihana, L., \& Gordon, C. (2013). Commencing nursing students' perceptions and anxiety of bioscience. Nurse Education Today, 33(11), 1399-1405. https://10.1016/j.nedt.2012.10.020

Doyle, K., Sainsbury, K., Cleary, S., Parkinson, L., Vindigni, D., McGrath, I., \& Cruickshank, M. (2017). Happy to help/happy to be here: Identifying components of successful clinical placements for undergraduate nursing students. Nurse Education Today, 49, 27-32. https://doi.org/10.1016/j.nedt.2016.11.001

Epstein, R. M. (2007). Assessment in medical education. New England Journal of Medicine, 356(4), $387-396$.

Forbes, H., Oprescu, F. I., Downer, T., Phillips, N. M., McTier, L., Lord, B., Barr, N., Alla, K., Bright, P., Dayton, J., Simbag, V., \& Visser, I. (2016). Use of videos to support teaching and learning of clinical skills in nursing education: A review. Nurse Education Today, 42, 53-56. https://doi.org/10.1016/j.nedt.2016.04.010

Glasow, P. A. (2005). Fundamentals of survey research methodology. http://www.uky.edu/ kdbrad2/EPE619/Handouts/SurveyResearchReading.pdf

Henderson, A., Cooke, M., Creedy, D. K., \& Walker, R. (2012). Nursing students' perceptions of learning in practice environments: A review. Nurse Education Today, 32(3), 299-302. https://doi.org/10.1016/j.nedt.2011.03.010

Hur, H. K., \& Roh, Y. S. (2013). Effects of a simulation based clinical reasoning practice program on clinical competence in nursing students. Korean Journal of Adult Nursing, 25(5). https://doi.org/10.7475/kjan.2013.25.5.574

Kavanagh, J. M., \& Szweda, C. (2017). A crisis in competency: The strategic and ethical imperative to assessing new graduate nurses' clinical reasoning. Nursing Education Perspectives, 38(2), 57-62. https://doi.org/10.1097/01.NEP.0000000000000112

Levett-Jones, T., Hoffman, K., Dempsey, J., Jeong, S. Y. S., Noble, D., Norton, C. A., Roche, J., \& Hickey, N. (2010). The 'five rights' of clinical reasoning: An educational model to enhance nursing students' ability to identify and manage clinically 'at risk' patients. Nurse Education Today, 30(6), 515-520. https://doi.org/10.1016/i.nedt.2009.10.020

Norcini, J. J., \& McKinley, D. W. (2007). Assessment methods in medical education. Teaching and Teacher Education, 23(3), 239-250. https://doi.org/10.1016/j.tate.2006.12.021

Ralph, N., Birks, M., Cant, R., Chun Tie, Y., \& Hillman, E. (2017). How should science be taught to nurses? Preferences of registered nurses and science teaching academics. Collegian, 24(6), 585-591. https://doi.org/https://doi.org/10.1016/j.colegn.2017.01.004 
Salamonson, Y., Weaver, R., Chang, S., Koch, J., Bhathal, R., Khoo, C., \& Wilson, I. (2013). Learning approaches as predictors of academic performance in first year health and science students. Nurse Education Today, 33(7), $729-733$. https://doi.org/10.1016/j.nedt.2013.01.013

Schmeck, R. R. (2013). Learning strategies and learning styles. Springer Science \& Business Media.

Scully, N. J. (2011). The theory-practice gap and skill acquisition: An issue for nursing education. Collegian, 18(2), 93-98. https://doi.org/10.1016/j.colegn.2010.04.002

Ventura, S., \& Onsman, A. (2009). The use of popular movies during lectures to aid the teaching and learning of undergraduate pharmacology. Medical Teacher, 31(7), 662-664. https://doi.org/10.1080/01421590802641489

Yoo, M. S., \& Park, H. R. (2015). Effects of case-based learning on communication skills, problem-solving ability, and learning motivation in nursing students. Nursing and Health Sciences, 17(2), 166-172. https://doi.org/10.1111/nhs.12151

\section{Please cite this article as:}

Macartney, M.J., Namasivayam, P., \& Cooper, J.F. (2021). Student nurse perceptions of video simulation and critical reflection for developing clinical-reasoning skills: A cross cohort study. Student Success, 12(1), 47-55. https://doi.org/10.5204/ssj.1653

This article has been peer reviewed and accepted for publication in Student Success. Please see the Editorial Policies under the 'About' section of the Journal website for further information.

Student Success: A journal exploring the experiences of students in tertiary education

Except where otherwise noted, content in this journal is licensed under a Creative Commons Attribution 4.0 International Licence. As an open access journal, articles are free to use with proper attribution. ISSN: 2205-0795 